\title{
Satish Dhawan, the academic who professionalized space research in India
}

\author{
Ramabhadran Aravamudan* \\ K5/3, 10th Cross, RMV Extension, Sadashivanagar, Bengaluru 560 080, India
}

THEY were born about a year apart, but a hundred years after their birth they are still remembered for their outstanding contribution to the establishment of India as one of the leading space-faring nations of the world. Vikram Sarabhai was the visionary who dreamed of India 'leapfrogging' to a developed country utilizing space technology. In the short span of less than a decade, he created a highly motivated band of scientists and engineers to develop from scratch the expertise needed for building rockets and satellites that would launch the country into the space age. Alas, he could not live to see his dream fulfilled and passed away at a young age of 52 years. Satish Dhawan, took over the task where Sarabhai left and in the dozen years he was in charge, converted the organization into a professional body with a clear focus and well-defined goals fully endorsed by the nation.

Born into a well to do family, Dhawan had an elite upbringing, with degrees in mathematics, physics, mechanical engineering and strangely, a Master's degree in English literature. He then proceeded to USA to earn his $\mathrm{MS}$ and $\mathrm{PhD}$ in Aeronautical Engineering. His specialization was in experimental fluid dynamics. A teacher by temperament, he chose to be an academic and joined the faculty of the Indian Institute of Science (IISc), Bangalore in 1951 and became its Director in 1962, the youngest at an age of 42 years. It was in 1971 that he took a year's sabbatical leave and was at the California Institute of Technology (Caltech), USA, as a visiting professor.

By 1971, space research activities in India had progressed well with an active sounding rocket programme and the beginnings of work on the development of a modest satellite launch vehicle capability. Teams were identified for defining the specifications of the various elements of the rocket and the requisite ground elements. Facilities for fabrication and production were under construction. Teams of scientists and engineers were recruited for the challenging tasks ahead. Sarabhai was the inspirational leader who motivated the entire team and interacted personally with them to formulate development plans and schedules. The organization was at a formative stage at this time and the management structure was not frozen, the teams interacting directly with Sarabhai for

*e-mail: aravamudan37@gmail.com major decisions. There was also a certain amount of duplication of work, perhaps as a deliberate strategy in the initial stages, which had to be resolved. Budgets were increasing and public accountability was becoming paramount.

It was at this crucial juncture that the organization received a severe jolt. Sarabhai was on one of his routine visits to Thiruvananthapuram during the last week of December 1971, to review the progress made in the development tasks. As usual he was staying at the Kovalam beach in the quaint Halcyon Castle which had been converted into a small hotel. After spending the day at Thumba and Veli Hills discussing with the various technical groups, the meetings spilt over to Kovalam where the talks and presentations continued well into midnight. Some of us left for our homes even as Sarabhai was still busy talking to a few colleagues. Imagine our shock, when we heard the next morning, on 30 December 1971 to be precise, that Sarabhai had passed away in his sleep. His death was so sudden and shocking that we did not know what hit us. The long-term programmes of the organization were just being formulated. We were getting our funding sorted out and were transitioning into serious project mode. At this critical moment we were left leaderless. Sarabhai had not named a second in command or even groomed a successor.

There was an air of uncertainty for a few days as the Prime Minister (PM), Indira Gandhi consulted various advisors before she zeroed in on a successor. She decided to appoint the brilliant and stylish Caltech-trained aeronautical engineer, Satish Dhawan as the person to carry forward the torch. Dhawan was an experienced man with a proven track record. However, he told the PM that he could not join immediately as he was committed to Caltech for a few more months. He also had some other stipulations. He would join only if he could simultaneously continue as the Director of the IISc and he also wanted to locate the Indian Space Research Organisation (ISRO) Headquarters (HQ) in Bengaluru.

Indira Gandhi agreed to everything. She requested the eminent physicist M. G. K. Menon to hold the fort until Dhawan could take over. Menon functioned as the Chairman of ISRO from January to September 1972.

Dhawan returned to India after his stint at Caltech and took over as the Chairman of ISRO by the end of 1972 . I can never forget his first visit as Chairman to Thumba. 
We were accustomed to Sarabhai's visits which often resembled some kind of endless durbar - the entire place would be abuzz with activity and everyone milled around him, trying to capture his attention. We did not know what to expect of the new Chairman.

That day all of us waited with great anticipation for this professor about whom we had heard so much. We wanted to flood him with reports and proposals. I arrived at the airport early and as was the practice in those innocent pre-high-jacking days, walked straight onto the tarmac. I was surprised to see our resplendently turned out CISF men lined up almost to the bottom of the mobile staircase of the aircraft. In an attempt to impress the Chairman, Kulkarni the administrative controller had ordered our entire CISF force to form a guard of honour to receive the boss at the airport.

I will never forget Dhawan's expression of shock and surprise when he got down from the aircraft along with the other passengers. At first, he thought the guard of honour was for some other VIP. Later, he realized it was for him and not for some top military brass. He was then ceremoniously escorted to Thumba with motorcycle outriders followed by a procession of official cars. By the time we reached Thumba, his surprise turned into annoyance. Having been an academic all his life, he obviously disapproved of pomp and ceremony.

At Thumba he was introduced to the senior officials who took him round some of the laboratories and gave him a presentation of the ongoing activities. It was now beyond working hours, but the milling crowd of scientists and engineers was still around him. We were all accustomed to Sarabhai's style of functioning and assumed the new chairman will continue to work through the evening until midnight and beyond.

Suddenly Dhawan looked around. 'Why are you all still here?' he asked. 'Is it not time for you to go home?' We all stopped in our tracks. How could we leave the Chairman and go home at this time? But Dhawan was adamant. He gently told us to take a break and come back refreshed the next day.

It took us some time to get used to this new style of functioning, which was more practical, systematic and level-headed. Sarabhai's management style was that of a patriarch dealing with a small, well-knit family. It was a kind of monolithic structure and he operated on a one-toone basis. There were no formal systems in place, with parallel technical teams operating, sometimes working on similar systems without much coordination. This was fine and even desirable when the organization was just building up. But now the time had come to invest large amounts of public funds and the casual style of management had to change. Accountability to Parliament and the public for the money spent needed to be ensured and results shown. This was when Sarabhai the father figure passed away and Dhawan the academic took over. And he brought in a totally new style of functioning.
Dhawan's first task was to bring some order into the widely dispersed teams by integrating them and defining their individual roles and collective responsibilities. This he did by forming programme-based centres with undisputed leadership. He also organized a national level review of the long-term tasks of ISRO in consultation with internal and external experts. The national agencies which would be the ultimate users of the products were also included in the dialogue. The recommendations and action items of this exercise were used to formulate the development plans and demands for grants from the Government.

Dhawan's style of management was quite business like. He followed the HQ-type of structure by hiring management-educated and experienced young men as shadow teams in the HQ. They would perform a technical and budgetary analysis of each programme, and provide him with daily feedback on the progress and indicate problem areas. He also introduced an elaborate annual budget exercise. Senior personnel from all the centres were assembled in the HQ. The directors and project managers presented their proposals in open forums. Searching queries and clarifications could be raised by anyone present, irrespective of hierarchy. This ensured there was clarity and no duplication. Meanwhile the band of management specialists from the HQ whom we had nicknamed 'the blue-eyed boys', would take frantic notes and ask tough questions.

The change in style was difficult to deal with at first. But soon we realized that this kind of change was inevitable given the increasing complexity and size of the budgets involved. The scrutiny became more rigorous. Our new Chairman was a dignified man with great intellectual honesty. He encouraged honest criticism and was quick to recognize merit. He was quite systematic with a no-nonsense style.

Dhawan was particular that the local industry and academia should be associated with the programme, and that there should be a two-way dissemination and absorption of expertise. So, he inducted organizations like HAL, BEL and institutions like IISc, IITs and other Government laboratories to partner ISRO. Under a programme titled RESPOND, small grants were made to various research teams to undertake specific projects for space research.

The space research activities during Sarabhai's tenure were coordinated by the Department of Atomic Energy, but Dhawan decided that the time had come to create an independent Government department for space research. So the Department of Space (DoS) was formally established with a Space Commission directing the programme, somewhat on the lines of the Atomic Energy Commission. In the Government resolution forming the Space Commission, which was drafted by Dhawan, he made sure that the professionals were insulated from the drudgery of bureaucracy. His draft read, the Space 
Commission and the DoS are being set up in order to promote a rapid development of activities connected with Space Science, Space Technology and Space Applications, the Government of India consider it necessary to set up an organisation, free from all non-essential restrictions or needlessly inelastic rules, which will have the responsibility in the entire field of Science and technology of Outer Space'.

Having been brought up as an academic and researcher, Dhawan knew that ultimately the value of investment in space research lies in its real applications to the rapid development of the nation and society in general. He therefore set about creating interfaces with the user communities for effective planning and utilization of the capabilities generated and also to provide mid-course correction, wherever needed. He thus formed the INSAT Coordination Committee with membership from the Department of Telecommunication, Department of Information and Broadcasting, Department of Science and Technology, etc. to formulate and monitor the implementation of the INSAT system. This ensured that by the time the INSAT satellite and the corresponding ground segment were ready, the users were prepared to utilize the same system. Similarly, to overview and implement the remote sensing, programme, he created the National Natural Resources Management System (NNRMS), overview committee for coordinating the creation and utilization of remote sensing data from the IRS satellites. For monitoring work on space sciences, he formed an Advisory Committee on Space Sciences (ADCOS). Thus, Dhawan ensured that both within the organization and outside among the user agencies, effective systems were put in place to generate and absorb the fruits of space research for the rapid development of the country.

Dhawan's colleagues at ISRO remember him for his integrity and large-hearted nature. The early days of SLV development were fraught with many technical problems and reverses. There were dramatic failures which left the development teams frustrated. Dhawan, ably supported by the venerable Brahm Prakash, who was Director of the Vikram Sarabhai Space Centre, made sure that the teams did not lose heart and encouraged them to learn from the failures and overcome the problems. As A. P. J. Abdul Kalam, the man entrusted with SLV development used to remark, Dhawan being a noble leader would assume personal responsibility for the failure, but when the mission succeeded, he would let his younger colleagues take the credit. He was also particular that the failure analysis should be kept transparent with the widest participation of engineers and scientists, irrespective of their rank. This set the tone for the future practice in ISRO as to the method of handling failures and improvement of reliability. He realized that being a high-risk enterprise, space technology needed to pay great attention to quality and reliability as well as safety. Personally, he assigned me the task of organizing a HQ-level overview body for ensuring uniform reliability practices across the organization. Similar arrangements were made for safety practices, especially since ISRO handled a large amount of hazardous materials and processes.

One of the major contributions of Dhawan was the induction of the industry and academia into the process of design, development, fabrication and utilization of space hardware and systems. He was of the firm conviction that while ISRO will benefit by this relationship, the industries and academia will also thrive by this association. Thus, today one sees industries making important rocket hardware, satellite subsystems and ground support equipment, and gradually the complexity of systems manufactured outside ISRO has been increasing. As a consequence, ISRO's capacities have been better deployed for important R\&D work.

This concept of Dhawan has assumed such a national importance that the Government of India has considered it expedient to throw open the space sector to private enterprise and start-ups to undertake end-to-end activities. The Government feels that an open and inclusive space sector would accelerate job creation, innovation and growth. With this in view, orders have been issued to create an autonomous nodal agency called the Indian National Space Promotion and Authorization Centre (IN-SPACe) under DoS as a separate vertical for permitting and regulating the activities of the private industry in the space sector. This will be the nodal agency to handhold and promote private endeavours in the space sector, and ISRO will share its technical expertise as well as its facilities with them.

Dhawan's efforts to streamline the organization not only covered the scientific and technical elements, but also the administrative and human resources aspects of ISRO. In this he was ably assisted by outstanding bureaucrats like M. K. Vellodi, T. N. Seshan and similar stalwarts. In the initial years, employees were inducted into the organization from various sources and at various times on different terms. There was thus a wide range of salaries and wages for persons with the same qualifications and experience. And these persons had to work together. This led to a lot of heartache and dissatisfaction. Dhawan ordered a scheme for the normalization of the terms of employment. This was a major effort which demanded the active attention of scientists and administrative staff to the point of impacting on the development schedules. But Dhawan felt that it was vital to set things right and that employee satisfaction was paramount for progress. Many anomalies were sorted out during this process. We slogged hard in this regard, working overtime to define formulas for rectifying the anomalies, knowing that perfect solutions are impossible. Undoubtedly, this exercise vastly improved the job satisfaction level among the employees.

Another important change Dhawan brought about was in respect of performance evaluation of personnel and 


\section{SATISH DHAWAN BIRTH CENTENARY}

their career advancement. While the kind of projects and their application were the motivating factors in an employee's work output, it was also necessary to assess and reward merit in a fair and transparent manner so that excellence of innovation and performance could be maintained. Dhawan introduced a system of in situ promotions for scientists after periodic evaluation, doing away with the usual governmental requirement for creating vacancies. This evaluation was a biannual exercise across the board. External experts from the academia and industry were co-opted into the committees to ensure fairness and transparency.

As the employee strength increased, labour unions and staff organizations with different political affiliations appeared and their demands had to be attended to. Dhawan firmly believed that their legitimate grievances had to be addressed without adopting a confrontational approach. He thus created what is termed the Joint Consultative Machinery (JCM), with membership from the staff side and the management side to formally raise issues and find agreed solutions. This was affiliated to the national-level JCM at the Central Ministry of Labour.

I had earlier mentioned how Dhawan insisted on involving all the scientists and engineers in formulating and reviewing annual budgets so that there would be awareness of the objectives and problem areas of major programmes. He also firmly believed that there should be transparency in assessing the progress of major projects and their milestones. He formalized the regular holding of national-level programme reviews when the project managers were made to present their status and problem areas. Acknowledged experts from across the country were invited to the reviews to give their comment and suggestions for improving the reliability and efficiency of the systems.

In conclusion, Dhawan, the academic was suddenly confronted with the responsibility of propelling India into the band of leading space-faring nations of the world. During his tenure of a dozen years at the helm, he turned an amorphous group of enthusiastic scientists into a wellknit organization of professionals who could conceive, plan and implement major programmes as well as any agency in the world. He groomed his successors carefully and ensured the continuity of the programmes. The resounding success and reliability of ISRO's endeavours are indeed a testament to his foresight and vision. Even after his retirement, Dhawan continued to participate in the developmental programmes of ISRO and had a permanent presence in the ISRO HQ, ready to meet and advise senior scientists without interfering in the day-today matters.

Satish Dhawan left his permanent mark on India's space capabilities. He passed away on 3 January 2002. A century has passed since the birth of this remarkable son of India. If he were alive today, he would be delighted to see the progress made by the organization that he so caringly nurtured and made it a model to emulate.

doi: $10.18520 / \mathrm{cs} / \mathrm{v} 119 / \mathrm{i} 9 / 1448-1451$ 